\title{
SELF-EFFICACY BELIEFS AMONG SCHOOL MATHEMATICS TEACHERS OF NEPAL
}

\author{
Krishna Prasad Adhikari ${ }^{* 1} 凹$ \\ ${ }^{* 1}$ (MPhil. in Mathematics Education), Lecturer, Tribhuvan University, Kirtipur, Kathmandu, Nepal
}

DOI: https://doi.org/10.29121/granthaalayah.v8.i7.2020.694

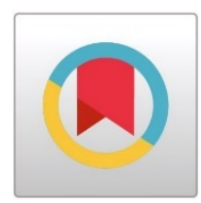

Article Type: Research Article

Article Citation: Krishna Prasad Adhikari. (2020). SELF-EFFICACY BELIEFS AMONG SCHOOL MATHEMATICS TEACHERS OF NEPAL. International Journal of Research -GRANTHAALAYAH, 8(7), 192-204. https://doi.org/10.29121/granthaa layah.v8.i7.2020.694

Received Date: 09 July 2020

Accepted Date: 30 July 2020

Keywords:

Self-Efficacy

Abductive Process

Student Engagement

Classroom Management

Instructional Strategy

\section{ABSTRACT}

Self-efficacy belief of the teacher is widely accepted construct in the professional development of the teacher. In this context, I as a mathematics teacher interested to study the efficacy beliefs of mathematics teachers in Nepal, which is a major contributing factor for teaching mathematics effectively. In this research, I, specifically, focused on exploring the selfefficacy beliefs of mathematics teachers in three aspects: student engagement, instructional strategy, and classroom management and to analyze the different contributing factors in the development of efficacy beliefs by using explanatory sequential mixed-method research. I chose 214 mathematics teachers randomly from Kathmandu district for a survey and 15 mathematics teachers from 214 mathematics teachers who participated in survey purposively for interviews. Adjusted Teacher's SelfEfficacy Scale containing 15-items were used for survey and semistructured interview schedule for interview. Descriptive as well as inferential statistics were used to analyze the self-efficacy beliefs of teachers and inductive approached used for the data obtained from interview. At last, I integrated both quantitative and qualitative results to deduce the findings and conclusion of the study. The result shows that teachers have good efficacy beliefs in teaching mathematics. Teachers have better efficacy beliefs in instructional strategy than in the other two. Experienced teachers have significantly higher self-efficacy beliefs than novices. Despite the huge investment of government in the teachers of public school, institutional school's teachers have better self-efficacy beliefs in teaching mathematics. Teaching experience, teacher's engagement in professional activities, mathematical and pedagogical content knowledge, and working environment of the school are major contributing factors in the development of the self-efficacy beliefs in mathematics teachers. There are so many factors in the development of self-efficacy of mathematics besides professional training, so stakeholders should focus on other aspects as well.

\section{INTRODUCTION}

Teacher's effectiveness on teaching mathematics in Nepal always becomes an issue of debate, especially, after the declaration of school education examination (SEE) result. This debate also back-up by different study

(C) 2020 The Author(s). This is an open access article distributed under the terms of the Creative Commons Attribution License, which permits unrestricted use, distribution, and reproduction in any medium, provided the original author and source are credited. 
commission reports, which have exposed that teachers' capacity, confidentiality, motivation, and commitment in teaching sectors have been downing (Giri, 2014). The authorities of state have been continually blaming the teachers for not giving better performance in teaching. But, actually, such types of critics on teachers can never create positive vibes to make mathematics teaching and learning effective and productive. Looking at the worst result of students in mathematics, blaming the teacher on that is unfair because there are so many factors besides that. A weak and psychologically disinterested and depressed teachers cannot perform better in their profession (Khany \& Malekzadeh, 2015). Teachers should have a strong belief on their profession and the pedagogy they have been using in the classroom. Surely, the teachers can play most important role for the development of mathematical identities in students (Cobb \& Hodge, 2002). They can influence the students' ways of thinking in the creation of knowledge as well (Walshaw, 2004). The efficient teachers can establish the equitable arrangements giving attention to the different needs of students. Only the positive attitude on teacher can raises the student's comfort level, enlarge their knowledge base, and gives them greater confidence in their capacity to learn and make sense of mathematics (Anthony \& Walshaw, 2009). These aspects of the teaching and learning process are tightly interlinked with the efficacy beliefs of teachers.

The term efficacy explains how a person can accomplish tasks or goals, use strategies, or maintain the necessary motivation required to accomplish the set tasks or goals. This includes all the activities which teachers accomplish in their teaching activities (Turkoglu, Cansoy, \& Parlar, 2017). Analysis of every facet of education only through the lens of students' achievement may not uncover the root cause. There are so many other constructs which directly or indirectly linked with the student's success. Self-efficacy beliefs of teachers would be one of the important constructs in educational success which is placed on the shadow in the field of research in Nepal. Teachers who do not feel confident in their ability and activities may not be able to produce the students who meet our standards in terms of grades, behaviour, and motivation.

\section{TEACHING MATHEMATICS AND SELF-EFFICACY BELIEFS}

In my view, mathematics can be a difficult subject to learn, especially the formal ways in which we teach mathematics that does not always align with student's mathematical thinking. Mathematics is a natural part of our existence, yet it is often taught as though it is a mysterious and enigmatic entity. Teaching mathematics means not only to teach contents of mathematics but also contains multitude of challenges such as difficult students and/or poor student's attitude toward learning mathematics, inadequate teacher training to teach mathematics, insufficient mathematical content knowledge, diversified classroom, varying mathematical abilities and background of the students (Brown \& McNamara, 2011). We have been teaching mathematics as an independent body of knowledge disconnecting with our daily life activity. I think this causes the problem in mathematics teaching-learning. The teacher and teaching process cannot be distracted from the context. So, teaching is not an easy job, it requires proactive behaviors, persistence, motivation, and a positive physiological state. These constructs are closely related to the self-efficacy of the teacher (Bandura, 1994).

Teacher's professional development programs in Nepal are completely tied up with the student's achievement but we rarely concern analyzing the effectiveness of the program on teacher's self-efficacy development process. A teacher should be committed, competent, and confident to transform the teaching into learning process. For this, self-efficacy is the fundamental aspect because it is about the sense of obligation to their student and feeling responsible for their academic, emotional, and social well-being (Bandura, 1977a). More specifically, teacher's selfefficacy is concerned with the willpower of a teacher to improve his/her students' learning. Better educational outcome is only possible when teachers have a high level of self-efficacy beliefs on their teaching-learning activities. (Turkoglu, Cansoy, \& Parlar, 2017).

The rapidity of social and technological change is placing teachers into a new and unknown educational frontier with limitless potential. Nowadays, students do not need access to the information, but they need the skills to filter, use, think about, analyze, be critical of, and navigate the overwhelming amount of information (Ball, Hill, \& Bas, 2005). In this situation, only the mathematical content knowledge is not enough to teach students, they required the skill of managing classrooms, designing instructional strategy, and engaging the students in learning. Student engagement is a contributing factor to increase self-efficacy belief of teacher (Covell, McNeil, \& Howe, 2009). On the return, teachers with high sense of efficacy beliefs can put extra effort on design, manage and engage their students in the intended instructional process. Self-efficacy for teaching also influences how a teacher thinks about teaching, 
Krishna Prasad Adhikari

what they teach, how they teach, how effective (or ineffective) they feel in their teaching will be, their motivation to teach, the goals they set for themselves and their students, and their resiliency to endure the difficulties of the profession.

\section{THEORETICAL UNDERSTANDING}

Social Cognitive Theory postulated by psychologist Albert Bandura in 1977 is the philosophical base for selfefficacy construct. The social cognitive theory advocates that individuals as active agents, whose interpretations of the results of their performances inform and alter through their "environments and self-belief, which in turn inform, and alter their subsequent performances" (Pajares, 1996, p. 542). Borrowing the term of Bandura (1986), 'triadic reciprocal causation', which interplay with the dynamic relationship between behavior, personal factors (cognitive, affective, and biological), and environmental factors, contribute to the development of self-efficacy beliefs in the individual. In social cognitive theory, people exhibit some influence over what they do because they are proactive and self-regulating (Skaalvik \& Skaalvik, 2010). According to social cognitive theory humans can self-reflect, thinking about and learning from their pasts and hence they can self-regulate and can plan alternative strategies and have forethought in the various situation (Pajares, 1995).

Bandura's social cognitive theory stresses the significance of cognition influence on people's capability to encode information, self-regulate and perform the behavior. Bandura labeling this theory as "cognitive" since a lot of the human behavior and actions are aforethought based on 'cognized goals' or pre-determined thinking of one's capabilities (Bandura, 1989).

For the current study, this theory can be helpful to identify a teacher's belief, behavior, and context that interplay and influence each other. For instance, personal factors of a teacher such as perceived ability on content knowledge of mathematics and efficacy beliefs for teaching tasks may influence teaching behavior, simultaneously this behavior may influence beliefs and other personal factors, and both may also be influenced by contextual factors such as working school's academic environment, interpersonal relationship, status of the school, job security, and so on. Teachers' beliefs in their abilities to instruct students can influence students' performance, which is a strong predictor of instructional effectiveness (Al-Alwan \& Mahasneh, 2014). It is worth noting that perceived self-efficacy is not a measure of the individual skills rather than the individual beliefs on his capabilities and what the individual can do under certain conditions regardless of what skills the individual has. Moreover, Bandura (1977b, p. 37) explains that "different people with similar skills, or the same person under different circumstances, may perform poorly, adequately, or extraordinarily, depending on fluctuations in their efficacy".

Self-efficacy beliefs concern the ability of an individual to perform the specific task. It is clear that the people with a high level of self-efficacy beliefs can develop the skill to accomplish the task better than the people with a low level of self-efficacy beliefs (Tschannen-Moran \& Hoy, 2001). So, self-efficacy belief is an important construct for a teacher to become hardworking as well as a successful teacher. Successful efficacy builders do more than conveys positive appraisals. In addition to raising people belies in their capabilities, they structure situations for them in ways that bring success and avoid placing people in situations prematurely where they are likely to fail often.

Based on the above arguments and different concepts and theories, self-efficacy is a simple yet powerful concept that can empower and activate teachers in their profession. In the review of different kinds of literature and concepts, the findings have linked teacher self-efficacy with many factors such as student outcomes in terms of achievement, motivation, self-efficacy and teacher outcomes like enthusiasm, persistence, instructional practices and commitment (Tschannen-Moran \& Hoy, 2001). Three dimensions, student engagement, instructional strategies, and classroom management, were identified in their research (ibid). Similarly, Gavora (2010) refers to a teacher's self-efficacy as a belief in the ability to plan, accomplish, and execute the instructional objectives. Self-efficacy of teacher can be improved through the integration of effective instructional strategies, a balance of engaging learning activities, and good classroom management (Skaalvik \& Skaalvik, 2014). I, in this study, also concerned about the self-efficacy beliefs of teachers in managing classrooms, developing the instructional strategies, and engaging students in learning mathematics. These three constructs are fundamental to measure and reflect on the teacher's self-efficacy (Al-Alwan \& Mahasneh, 2014). Skaalvik and Skaalvik (2014) further explained that teachers who considered themselves less competent in instructional strategies, classroom management, and student engagement reported a higher level of dissatisfaction compared to others. In addition to that, some detrimental factors for self-efficacy beliefs are also described in this paper. 
Self-Efficacy Beliefs Among School Mathematics Teachers of Nepal

\section{METHODS AND PROCEDURES}

In the present study I used explanatory sequential mixed-method design because in my study quantitative data informed qualitative data (Creswell, 2015). This type of research is attaining increasing acceptance in social sciences including education (Creswell \& Plano Clark, 2011). However, I claim that collecting qualitative and quantitative data is not new, what is new is combining both forms of data and presenting them as a distinct research design (Creswell \& Plano Clark, 2011). Pragmatism is the philosophical assumption of this methodology (Creswell, 2015). The philosophical theory of pragmatism is seen as a means of bridging the gap between the empirical singular scientific approach to research and the newer carefree inquiring of qualitative research theories (Tashakkori \& Teddlie, 1998). Pragmatists felt that the real world could not be measured solely by a singular scientific method. So, to capture the real scenario, a mixed-method which is based on pragmatist philosophy was adopted in this research.

Methodologically, collected quantitative and qualitative data are mixed (Creswell \& Plano Clark, 2011) in this study, which is a process that not only enriches the research but completes it. In the first phase, quantitative data were collected to examine the self-efficacy of teachers through the questionnaire survey on school mathematics teachers of the valley area of Kathmandu district which comprises Kathmandu Metropolitan and Kirtipur Municipality. Altogether, 214 mathematics teachers where 109 from institutional and 105 from public schools, were selected randomly for a questionnaire survey. In the qualitative phase, I selected 15 mathematics teachers for the interview, representing from a basic and secondary level; male and female; experienced and novice; institutional and public schools purposively. The purpose of interview was to back up the data from questionnaire and explanation of the different detrimental factors on self-efficacy beliefs of teaches.

The Teachers' Self-Efficacy Scale (TSES), which was used in this study, was first published in 2001 by Tschannen-Moran and Woolfok Hoy and has been used and adapted widely since then (Tschannen-Moran \& Hoy, 2001). The scale was designed in two measures: a 24-item scale and a 12-item scale comprising three main dimensions that cater to the multi-dimensionality of sense of efficacy: efficacy for student engagement, efficacy for classroom management and efficacy for instructional strategy. To lessen the response time for the participants and covers the areas of teacher's efficacy based on the context of Nepalese mathematics teaching, the 24-items efficacy scale was adjusted to 15-items scale after the pilot survey. The TSES was in 5-point, where 1 for nothing, 3 for very little, 5 for some influence, 7 for quite a bit and 9 for a great deal. A response of 1 represents the lowest efficacy rating while 9 accounts for the highest efficacy rating with each item.

The adjusted 15-items scale had Cronbach's alpha value 0.88 (Mean=6.88, SD=1.14). For three factors, in student engagement 0.80 Cronbach's alpha value with mean 6.94, SD 1.24, in classroom management Cronbach's alpha 0.82 with mean value 6.67 and SD 1.37, and for instructional strategy, Cronbach's alpha 0.81 with mean 7.02 and SD 1.23. The Cronbach's alpha if item deleted also calculated to explore the item defects, all the values were less than the Cronbach's alpha, so it is not necessary to change any item in the scale. The data presented here show that the scale consisting of 15 items' scale for self-efficacy was consistent.

I used a semi-structured interview schedule in the second phase of the study, to explore the determining agents in the development of self-efficacy beliefs on mathematics, combining the features of the structured and unstructured interview. Cohen, Manion, and Morrison (2007) asserted that the type of interview carried out can be determined by the nature and aim of the research, as different research aims necessitate different levels of structure and types of questions. Careful consideration was therefore given to the aims and research questions of the current study. First, I believed that this technique would be to collate the particular data needed for the research more efficiently. Using predetermined questions would enable me to guide and focus the interviews on the study aims. This technique would also provide the opportunity to expand on interviewees' responses, allowing the researcher to dig deeper into their personal experiences to gain more detailed pieces of information. The schedule began with general questions regarding the concept of self-efficacy and the importance of efficacy in teaching mathematics, how their confidence level on the subject matter changed over time, what factors contributed to the development of selfefficacy in mathematics. To ensure the validity of the content of the interview schedule, an initial assessment was carried out. This was essentially done through discussions with the research supervisor, followed by showing the interview schedule to my seniors to elicit their opinions and suggestions on the objectives and appropriateness of the questions.

Since this study was done in two phases, quantitative followed by qualitative. Qualitative phase was started only after the analysis of the data obtained from the questionnaire. For the quantitative phase, I distributed a questionnaire to 304 mathematics teachers who accepted my request to participate in the study. Before the 
distribution of the questionnaire, I explained my purpose of the study and guaranteed the secrecy of the responses. I myself distributed the questionnaire to each teacher and collected it after a week. But, only 214 completed and returned the questionnaire. I coded all the data gathered in response to the questionnaire by assigning the ID of the participant. After that, I entered these data on my personal computer and analyzed using SPSS software. I calculated the mean, standard deviation, ANOVA, and t-test.

After the completion of quantitative analysis, I framed the interview guidelines and conducted an interview with 15 mathematics teachers whom I selected during my field visit on a questionnaire survey. It took 12 days to complete the interview. In the process of the interview, I encouraged the participants to provide reliable and honest responses as they could. I also explained the importance of the interviewees' opinions that they would provide the researcher with a holistic understanding of the topic and enrich the study. I also informed to each interviewee that there would usually be no right or wrong answer. Besides that, I emphasized all information would remain confidential and that they had the right to withdraw at any time, as outlined in the information sheet. After each response, I usually gave a brief summary of what the interviewee had said so that the participants could confirm whether I had correctly understood the information they had given. This is a very important aspect in order to develop an accurate understanding of interview data. I recorded all the interview, after receiving consent from teachers. As soon as each interview completed, I imported the audio recording to my personal computer and transcribed it in the Nepali language. I thematized and analyze the responses using the inductive process. Different themes were developed completely based on responses. The choice of thematic analysis for this research lies in its flexibility, suitability to a pragmatic framework, ease of use, acceptability academically because it provides a thick description of data and the ability to highlight connections and alterations across the data sets.

In this study, data were analyzed separately and then merged. This is an appropriate approach to take in explanatory mixed-method design (Creswell \& Plano Clark, 2011). Both inductive and deductive reasoning were employed. Morgan (2007) labeled this integration of approaches as 'abductive', a combination of inductive and deductive approaches. Abductive approach aimed at getting the most out of the quantitative and qualitative data sets by seeking useful points of connecting them. The quantitative and qualitative analyses integration seemed to capture the richness of the two data sets and work out as a middle line between the subjectivity of the qualitative approach and objectivity of the quantitative approach, this approach is known as intersubjective approach (Morgan, 2007). The data was collected quantitatively and qualitatively in parallel but the aim in this study was not to test them against each other rather the quantitative and qualitative data were meant to be integrated to create a full picture of the whole situation.

Thorough my study, I tried to maintain confidentiality, anonymity, non-identifiability, and non-traceability of my respondents. The responses to the questionnaire and interview transcripts were kept confidential. The record will not be used in the future for any other research. The participants had the opportunity to listen to their interviews and were allowed to withdraw comments or erase some data. As a researcher, I myself were conscious about misinterpreting the result of the study. I have used unbiased language or words against gender, race or other groups of teachers as much as possible. Similarly, I have cited the literature that I referred during my study and references have been maintained accordingly.

\section{RESULT AND DISCUSSION}

\subsection{SELF-EFFICACY BELIEFS OF MATHEMATICS TEACHERS}

To answer the research question, "how do mathematics teachers perceive their self-efficacy on mathematics teaching? I used both quantitative and qualitative data. At first, I calculated mean, standard deviation, skewness and kurtosis value for each item of the scale. Data showed that the mean score on each item was greater than five. Since all the items have negative skewness value, so the responses on each item lie in the upper value. But, the skewness and kurtosis value were in range, so it indicates that the items were not substantially non-normal for a large sample size (Pallant, 2011).

After the analysis of the score on each item, I calculated the overall mean efficacy scores of teachers. The overall mean score on self-efficacy was 6.90 with a standard deviation of 1.18. It indicates that the teachers had good efficacy beliefs in teaching mathematics. 
The self-efficacy of teachers was also measured through the three dimensions: instructional strategy, classroom management, and student engagement. Table 1 shows the summary of teacher self-efficacy beliefs on these three dimensions.

Table 1: Summary of TSES on Three Dimensions

\begin{tabular}{|c|c|c|c|}
\hline Study Variables & N & M & SD \\
\hline Self-efficacy on Instructional Strategy & 214 & 6.99 & 1.30 \\
\hline Self-efficacy on Classroom Management & 214 & 6.76 & 1.34 \\
\hline Self-efficacy on Student Engagement & 214 & 6.96 & 1.27 \\
\hline
\end{tabular}

The result from the descriptive analysis showed that the mean score on instructional strategy (6.99) was highest among the three dimensions. There was a slight difference between the mean score on three dimensions of selfefficacy, however, the scores on classroom management and student engagement were below the instructional strategy implies that teachers had beliefs in planning and designing the strategy but they were not confirmed on the perfect execution of the plan. Two dimensions, classroom management and student engagement, are concerned with the lived activities of the classroom. If we cannot manage and engage students properly, we cannot apply our plan into the classroom. As a researcher, I felt that some of the teachers who participated in the survey did not know actually what self-efficacy is. So, in the interview, I asked the first question to the teacher about the concept of selfefficacy as it pertains to their role as a teacher. Most of the teachers explained efficacy as the ability to become a teacher. While some others defined it as ethical issues it includes the decision making in the teaching-learning process, persistence in the profession, confidence in their abilities. One teacher who was working as a mathematics teacher in public secondary school for 12 years expressed as, "I am a mathematics teacher because I teach mathematics, I can assess the students' level of understanding, I can manage and use different teaching-learning strategies based on the nature of content and level of students". This was the perfect answer to cover the major aspects of self-efficacy. From the interview with teachers, it can be said that teachers may not know the actual meaning of the self-efficacy but they were well known about all the activities which comprise self-efficacy in teaching mathematics (e.g. Turkoglu, Cansoy, \& Parlar, 2017). At least, our mathematics teachers had greater sense of selfefficacy. This belief is also crucial to test new methods and attempt novel ideas that can bring changes in student learning (e.g. Martin, Sass, \& Schmitt, 2012).

\subsection{TEACHING EXPERIENCE AND SELF-EFFICACY BELIEFS}

Different studies have exposed that teacher efficacy changes positively or negatively over time depending on the career development (e.g. Woolfolk Hoy \& Spero, 2005; Klassen \& Chiu, 2010). I also assumed that teaching experiences is crucial to develop the positive self-efficacy beliefs on teachers. Therefore, in this study, I also examine the self-efficacy beliefs among different teaching experiences groups of teachers by using descriptive as well as inferential statistics. Mean, standard deviation, minimum and maximum values were calculated under descriptive statistics and one-way ANOVA with post hoc analysis was used to test the significant difference between and among the three groups. Table 2 and 3 present the score obtained in both statistics.

Table 2: Descriptive Analysis for Different Teaching Experiences Group

\begin{tabular}{|c|c|c|c|c|c|}
\hline Teaching Experiences & $\mathrm{N}$ & Mean & SD & Min. & Max \\
\hline 1-5 years & 112 & 6.72 & 1.16 & 3.27 & 8.87 \\
\hline 6-10 years & 49 & 6.81 & 1.26 & 3.67 & 8.87 \\
\hline Above 10 years & 53 & 7.38 & 0.99 & 4.07 & 8.87 \\
\hline Total & 214 & 6.91 & 1.18 & 3.27 & 8.87 \\
\hline
\end{tabular}

Table 2 presents the mean and standard deviation of three teaching experienced groups. The mean score of teachers with above 10 years of experiences (Mean= 7.38) was higher than the two teaching experiences groups. But, the actual difference in mean and standard deviation scores between the groups was quite small. So the statistical analysis ANOVA was used to determine whether this difference is significant. From Table 3 , there was a statistically significant difference $(p=0.002<.05)$ efficacy scores for the three experienced groups. 
Table 3: One Way ANOVA among the Three Experiences Groups.

\begin{tabular}{|c|c|c|c|c|c|}
\hline & Sum of Squares & Df & Mean Square & F & Sig. \\
\hline Between Groups & 16.32 & 2.00 & 8.16 & $6.20^{*}$ & 0.00 \\
\hline Within Groups & 277.76 & 211.00 & 1.32 & & \\
\hline Total & 294.08 & 213.00 & & & \\
\hline
\end{tabular}

Note. * indicates significance at $\mathrm{p}<0.05$.

Table 3 shows there was a significant difference in mean score on self-efficacy among three teaching experienced groups but not signify between which two groups have significantly different mean scores on selfefficacy beliefs. So, to identify which two groups have a significance difference between the mean scores, the Post Hoc test was calculated. The result on the Post Hoc test shows that the mean scores of teachers with 1-5 years teaching experience is significantly different from the mean score of teachers with above 10 years of teaching experience. In addition to that, the mean score of 5-10 years of experience teachers is significantly less than the mean score of above 10 years of teaching experiences. This indicates that the teaching experience is one of the contributing factors in the development of self-efficacy beliefs. Teachers can develop their efficacy based on experiences in teaching and learning activities. Klassen and Chiu's (2010) study suggests that the teacher's self-efficacy rises from initial to mid-career and falls after 23 years of experience but this study disconfirms this finding that the self-efficacy of teachers grows corresponding to years of experience (e.g. Tschannen-Moran \& Woolfolk Hoy, 2007). From this finding, I confirmed that teaching experience is one of the detrimental factors in the self-efficacy beliefs of teachers.

Comparing efficacy beliefs between public and institutional school's teachers - We have two types of school, public and institutional, operating to provide formal education to the children. Public schools are those who get a regular grant from the government and institutional schools are operated and managed privately. We can see some dissimilarities between these schools in terms of facilities, teacher recruitment, performance, and so on. It is assumed that public school's teachers are more qualified, trained and competent than institutional school teachers. So, it is crucial to compare the self-efficacy beliefs of teachers of those schools. The comparison between the selfefficacy beliefs of public and institutional school teachers on teaching mathematics is presented in Table 4 . Table 4 presents the mean, standard deviation (SD), F score, and t-test value.

Table 4: Comparison between Public and Institutional Schools Teacher's Self-Efficacy Beliefs

\begin{tabular}{|c|c|c|c|c|c|c|c|c|}
\hline \multirow{3}{*}{ Self- Efficacy } & Nature of Institution & $\mathrm{N}$ & Mean & SD & $\mathrm{F}$ & Sig & $\mathrm{T}$ & Sig. (2-tailed) \\
\cline { 2 - 9 } & Public & 105 & 6.85 & 1.23 & .070 & .791 & -.704 & .482 \\
\cline { 2 - 9 } & Institutional & 109 & 6.96 & 1.12 & & & & \\
\hline
\end{tabular}

The mean and standard deviation (Mean=6.85, $\mathrm{SD}=1.23$ ) score of public school's teachers on self-efficacy is slightly lower than institutional (Mean=6.96, $S D=1.12$ ) school's teachers. Since the significance level of Leven's test is $0.79>0.05$, so, an equal variance was assumed between two groups. However, the scores of Table $4(\mathrm{t}(212)=-$ $0.704, p=0.482>0.05$ ) shows the difference between the mean scores of public and institutional schools' teacher was not significant.

This result is quite surprising for me because the qualification level of public schools' teachers was higher than the institutional schools' teacher in the survey. But, the efficacy score was lower than the institutional schools. That mean, level of education is not the detrimental factor for self-efficacy beliefs of the teacher. The reasons behind this result were explored in the interview. The teachers from institutional schools expressed that they had a good interpersonal relationship between the teachers, good management, disciplined students, clear vision, the regular meeting between staff and administration regarding teaching-learning activities and regular monitoring and supervision.

\subsection{FACTORS CONTRIBUTING THE SELF-EFFICACY BELIEFS}

The survey result shows that different backgrounds teachers have a different level of efficacy beliefs. It is also the developmental process based on cognitive processing and independent interpretation (e.g. Goddard, 2001). I interviewed with the 15 different backgrounds teachers and focused on to unearth their views about the contributing factors in the development of efficacy beliefs on an individual. Based on their views I developed four themes: 
Teaching experience, teacher's engagement, mathematical and pedagogical content knowledge, and working environment. These themes here I have considered as sub-heading and explained in-depth as far as possible.

Teaching experience - Teaching experience has seen as a noticeable factor among the teachers of mathematics. The quantitative result showed that the self-efficacy score of the teachers with an experience more than 10 years was significantly higher than the score of teachers with 1-5 years experiences with $F(2,211)=6.200$, and $p=$ $0.002<0.05$ in the ANOVA test. The Post-Hoc analysis showed that there was a significant difference in the mean score of teachers of experience 1-5 years and above 10 years and 6-10 years and above 10 years. This result indicates that developing self-efficacy beliefs is strongly based on the experiences of the teachers in teaching mathematics.

For qualitative data, I interviewed different teachers according to teaching experiences. I had teachers with more than 20 and less than two years of experience. As Bandura (1977a) experience is the major source of development of self-efficacy, the result of qualitative data also showed that experienced teachers were more likely to keep implementing instructional strategies that they believed to be effective from their long experience in teaching, they can differ their strategy based on the student's cognition level in a single class. One 18-year experience teacher expressed a little different strategy to control the classroom. She shared, "the more knowledge they (i.e. students) acquire, the easier it is to teach them, and their discipline. I believed that busy learners are more manageable. So, we always think of a conducive, cooperative and participated classroom". Three dimensions of selfefficacy are reflected in this version of the teacher. If you delivered mathematical content more comprehensively then students become more engaged in their learning and conducive, participative and cooperative classroom environment can be created (e.g. Fives \& Buehl, 2009).

Being strict is not a solution for effective classroom management. Experience has taught that it is sometimes necessary to maintain a relaxed atmosphere in class to feel at ease, for both teacher's and student's sake. One 11year experience teacher realized that, "having a little sense of humor and short time quiz or games between students in the classroom is required to create a good environment." His comment indicates that students do enjoy having an accommodating teacher who entertains during learning. Some teachers also argued that teaching the same level of students is important. The mastery of knowledge that teachers gained because of teaching the same level gives them a sense of efficacy that is solidified by repeated experience. One teacher to support this view expressed, "teaching in the same level throughout the years positively affected me, I became able to understand the psycho-social condition of my students according to their age, cognitive level, and interest, etc. from this knowledge I can choose instructional strategies that suit to my students according to the nature of content." Another teacher with 15 years of teaching experience expressed, "Initially, some students were not participating in classroom activities and exposing off-task behavior, but after some years I gained knowledge of students' learning psychology, interest and controlling the disruptive students and then all students started participating in the activities. I too changed my style of teaching and tone". This view reflects that throughout the years of experiences teacher can improve his/her teaching using various means. He/She can understand, monitor and evaluate the student's socio-psychological states. Teaching experiences cumulate abilities, knowledge, skills required for teaching the content.

Experienced teachers are equipped with the knowledge that enables them to see the sensitivity of the first encounters with their students to create the first impression with all its rules, ethos, and relationships which will last them a whole year. Experienced teachers talked about their ways of tackling problems such as constructive criticism, strict in-class rules, active learning versus mind wandering, lighting-class atmosphere through jokes, and empowering students' control over their learning. While novice teachers might have been extremely busy perhaps dazed by thinking of ways to teach and circumventing distraction that might lead to unnecessary confrontation with students and diversion from the main task, teaching. This discrepancy in the reaction of experienced and novice teachers could be attributed to experience. As Tschannen-Moran and Hoy (2007) reported, novice teachers mainly benefited from the availability of teaching resources such as different technological tools in teaching mathematics. They also favored using the information and communication tools in teaching mathematics than experienced teachers.

Another facet of self-efficacy which was very striking to teachers was student's engagement in learning. The major issue evolved during the interview was the demotivation of students in learning. Engaging students in learning is not only keeping students busy in doing work. Students may seem physically engaged but their minds could be wandering outside. About engagement, experienced teachers have different beliefs than novices. Experienced teachers expressed that their students would pay more attention and interest in the subject matter if the content was linked to real-world situations and applicability of content for future life, while novice teacher believed student's engagement is closely related to the understanding of the content, instructional strategy and their test result. They 
did not express any influence on their teaching. Teachers' confidence in engaging students in learning grows with years of experience. Different pieces of literature also support my finding but the finding from the research of Klassen and Chiu (2010) indicates that this pattern growing the efficacy in engaging student, managing classroom and using effective instructional strategies decline after 23 years of teaching.

Teacher's engagement - The interview with teachers showed that teacher's efficacy is linked to his/her commitment, as a result of being engaged at work. The teacher with high self-efficacy beliefs seemed engaged physically, emotionally and cognitively (Kahn, 1990). Highly engaged teachers also showed a sign of strong commitment and professionalism (Durksen \& Klassen, 2012). Most of the public school's teachers were trained and participated in different workshops. While the institutional school's teachers commented on government policy. Their voices inferred that the government has any policy to train teachers of institutional schools.

Mostly, the experienced and permanent teacher of public school expressed that training program is essential for the professional development and eventually it helps to enrich the efficiency of the teachers and hence its effects on efficacy beliefs of teachers. One trained mathematics teachers expressed as, "In my opinion, the regularity of the teacher training program is essential for the professional development of teachers. Which essentially effects on efficacy beliefs of teachers. Regarding the training contents and its effectiveness, contents which we plan to provide should be revised according to recent instructional technology, training should be in the form of workshops and participants should also be actively participated in training rather than a passive listener".

Teachers were not satisfied with the modality, content, and conduction of the training program. They suggested training should be in the form of workshop and participants should be engaged actively rather than listening to the lecture of experts.

The teachers who were engaged in their academic progression seemed more confident and committed to their profession. Engaged teachers tended to attribute their students' failure to themselves. They also focused on the autonomy of teachers to deliver their lessons. They had to depend on themselves to find suitable materials that suit their students' needs, learn how to manage the class and tackle disciplinary problems and find own methods to explain something to students. Self-efficacy is a strong predictor to motivate and furnish the behavior (e.g. Bandura, 1977a). Similarly, Woolfolk Hoy and Spero (2005) argue that self-efficacy is a powerful professional knowledge that all teachers need to equip themselves with. The result of the qualitative analysis showed that the engagement of teachers played a crucial role to develop the self-efficacy beliefs within themselves.

Mathematical and pedagogical content knowledge. In the interview, most of the teachers expressed that they are confident over the content of mathematics and quantitative results showed that teachers had good efficacy beliefs on instructional strategies. To become an efficient mathematics teacher, he/she should have fine subjectspecific concepts. Mathematical content knowledge is the combination of knowledge, skills, and understanding of the mathematical concept (e.g. Evans, 2011). The teachers who exposed high confidence in subject matters had good self-efficacy beliefs. One 28 years experienced teacher expressed her voice as, In the initial phase, I had some problems regarding content as well as pedagogical knowledge, however, I never stopped my labor and became a popular teacher with the years of teaching. I got so many offers to get tuition and coaching classes within and outside of the school. I became a very busy mathematics teacher very soon. That made me more responsible and accountable in my profession. Now I have been in the 28th year of teaching. Now I am a teacher trainer as well. The result of the study is also corroborated with the finding of Evans (2011), that teachers with high levels of content knowledge had higher self-efficacy beliefs and more positive attitudes towards mathematics. The study was done by Bates, Latham, and Kim (2011) exposed that teachers who lack procedural and content knowledge have lower self-efficacy beliefs.

My focus on this study was not to measure the content knowledge of teachers. But, I tried to explore how mathematical content and pedagogical knowledge of teachers play a role in developing the self-efficacy beliefs of teachers. The major theme of the results of qualitative data analysis showed that mathematical content knowledge is the primary component for effective teaching whereas pedagogical knowledge goes beyond the knowledge of the subject matter. When the teacher is more confident in his/her subject matter to teach then he/she can plan the lesson in more constructive ways. However, the teacher expressed their confidentiality on the mathematical content, they have very low knowledge of pedagogy and pedagogical selection to teach content. Pedagogy was the minor component of most of the teachers. They were very sincere on mathematical content and matter of teaching but lacked the basic concept of pedagogy. They were unknown about the curricular goals and objectives of the subject.

Most of the teachers had beliefs that mathematical content knowledge is the primary element to become an efficient teacher. In the process of teaching, we can learn about different instructional design and apply them to our classroom. The major part of the improvement in teaching and learning is our reflection on our teaching they viewed. 
Work environment - Work environment is also another crucial factor for self-efficacy development similar to Bandura's (1977a) verbal persuasion and social evaluation as the source of self-efficacy beliefs. In this study, the work environment refers to an institutional condition, interpersonal relationship, work-load, and position of teachers. The quantitative result of this study indicates that the mean score of institutional school teachers was slightly greater than that of public school's teachers. This result may be due to the academic working environment of institutional schools. One public school's mathematics teachers expressed her views as, "Here is no discussion about the academic excellence and student's success but mostly teachers discuss political issues". Most of the teachers of public schools accepted that political encroachment in schools is deteriorating the quality of schools. According to them, "Every teacher is a member of the teachers' union rooted in different political ideologies. The decision-making process of school was complete politically biased".

The teachers who expressed their interpersonal relationships with colleagues and administrators had high selfefficacy beliefs. One experienced teacher with high self-efficacy beliefs reported that his colleagues, coordinator, and principal sought his advice on certain issues related to academic activities. She expressed, "My colleagues are warm and caring aside from the fact that they are very professional in dealing with me. From both men and women's colleagues, I have struck a very friendly relationship with them which makes life and work and teaching much fun and easier. I enjoy going to school and in the classroom. The fact that my colleagues, coordinators and principal approach for me anything and ask my opinion makes me feel confident that I am doing okay with them and with my work and with my students." This view indicates that the teachers who work in highly collaborative environment have elevated self-efficacy. Such type of professional collaboration among staff fostered their self-efficacy beliefs' level (e.g. Woolfolk Hoy and Spero, 2005).

But, this was an ideal view I received from my respondents, except her, no one was happy with their institution. But, they have the belief that a good relationship is essential in the institution for a conducive environment. One added to the above view as, "When you are very positive with your institution and colleagues that makes you more positive to do the job. When you are with negative people or people who don't treat positively then you may lose your momentum". They only opined that the equilibrium relation is required between institutions and teachers and teachers and teachers but they did not feel accordingly. The equilibrium state can create momentum, in particular, the positive influence of others upon a teacher's behavior.

These findings corroborate with Bandura's (1977a) verbal persuasion theory on the development of selfefficacy beliefs. Bandura's social cognitive theory suggests that there is a reciprocal relationship between its three factors: personal factors, behavioral, and environmental. As cognitive theory suggest that teacher's self-efficacy beliefs should have a level of association with other contextual variables such as the environment which includes college itself, colleagues, students, management and possibly the resources/facilities and behavior of colleagues, students, management. The relationship between student and teacher plays a vital role in developing self-efficacy beliefs rather than the relationship between colleagues. This study revealed that high self-efficacy teachers set up good relations with students. They also understood the significance of building and maintaining teacher-student relationships for successful learning environment. One important finding from the interview was when highly selfefficacy teachers face misbehaviour in class, then this behaviour is not the cause of stress, rather, it can be viewed as a challenge (e.g. Collie, Shapka, \& Perry, 2012) A good relationship between colleagues and institutional elements plays a conducive role and develop positive vibes among the members of the institution. So, positive work ethos from colleagues motivates teachers to work hard. The data revealed from the interview shows that teachers with opined good interpersonal relationships between their colleagues, students and administration had higher selfefficacy beliefs on teaching mathematics.

\section{CONCLUSION}

Findings derived from the quantitative and qualitative phases of the study, I conclude that the teachers of mathematics have positive efficacy beliefs in teaching mathematics, specifically, they have confidence over selecting the appropriate instructional strategy, and they can control and manage the environment for teaching and learning activities and engage the students in learning mathematics. Teachers who have higher level of self-efficacy beliefs exposed low level of beliefs on classroom management and student engagement indicate that they have no sufficient level of efficacy on applying the designed strategy in the classroom. The findings of the study suggest that the experience of teachers in teaching mathematics is a significant contributor to the development of self-efficacy beliefs. 
Teachers' mathematical and pedagogical content knowledge is the primary and essential component for efficient mathematics teachers. Teachers without sound mathematical knowledge and strategy to deliver the content matter can't ever be an efficient mathematics teacher. Factors such as school environment, workload, interpersonal relationship, the position of teachers in school and society and professional engagement of teachers are also crucial for the development of self-efficacy beliefs on teachers.

Teachers in both public and institutional schools have a good efficacy level. But, I found institutional school teachers have better self-efficacy beliefs than public school teachers, however public school's teachers get better facilities than institutional school teachers. Actually, this was not the big research to generalize the finding for the whole context of Nepal. However, it is true that Kathmandu can hold a picture of almost parts of the country. So, even from this small-scale study, I can indicate some lapses in the public schools of Nepal. There may be problems in the part of school management, teacher's engagement and motivation, teachers' competency, or student's background, which demand huge and longitudinal research to establish the fact.

\section{SOURCES OF FUNDING}

This research received no specific grant from any funding agency in the public, commercial, or not-for-profit sectors.

\section{CONFLICT OF INTEREST}

The author have declared that no competing interests exist.

\section{ACKNOWLEDGMENT}

This paper is a part of my research in Master of Philosophy in Mathematics Education, Tribhuvan University, Nepal. My special gratitude goes to Professor Dr. Binod Prasad Dhakal, for his supervisory works during the study. I would like to thank the personnel of the University Grant Commission, Nepal, for funding support that helped to conduct this research.

\section{REFERENCES}

[1] Al-Alwan, A. F., \& Mahasneh, A. (2014). Teachers' self-efficacy as determinant of students' attitudes toward school: A study at the school level. Reveiw of European Studies, 64(1), 171-180. doi:10.5539/res.v6n1p171

[2] Anthony, G., \& Walshaw, M. (2009). Characteristics of effective teaching of mathematics: A view from west. Journal of Mathematics Education, 2(2), 147-164. Retrieved from http://www.researchgate.net/publication/228743535

[3] Ball, D. L., Hill, H. C., \& Bas, H. (2005). Knowing mathematics for teaching. American Educator, 14-46. Retrieved from http://www.aft.org/sites/default/files/periodicals/BallF05.pdf

[4] Bandura, A. (1977a). Self-efficacy: toward a unifying theory of behavioral change. Psychological Review, 84(2), 191-215. doi:10.1037/0033-295X.84.2.191

[5] Bandura, A. (1977b). Social learning theory. Englewood Cliffs, N. J.: Prentice Hall.

[6] Bandura, A. (1986). Social foundation of thought and action: A social cognitive theory. Englewood Cliffs, NJ: Prentice-Hall.

[7] Bandura, A. (1989). Human Agency in Socal Cognitive Theory. American Psychologist, 44(9), 1175-1184. Retrieved from https://pdfs.semanticscholar.org

[8] Bandura, A. (1994). Self-efficacy. In V. S. Ramachaudran, Encyclopaedia of human behaviour (Vol. 4, pp. 7181). New York: Academic Press.

[9] Bates, A., Latham, N., \& Kim, J. (2011). Linking pre-service teachers' mathematics self-efficacy and mathematics teaching efficacy to thier mathematics performance. School Science and Mathematics, 111(3), 325-333.

[10] Brown, T., \& McNamara, O. (2011). Becoming a mathematics teacher: Identity and idnetification (Vol. 53). Springer Science \& Business Media. 
Self-Efficacy Beliefs Among School Mathematics Teachers of Nepal

[11] Cobb, P., \& Hodge, L. L. (2002). A relational perspective on issues of cultural diversity and equity at they play out in the mathematics classroom. Mathematics Thinking and Learning, 4(2), 249-284. doi:10.1207/S15327833MTL04023_7

[12] Cohen, L., Manion, L., \& Morrison, K. (2007). Research methods in education (6th Ed.). New York, NY: Routledge.

[13] Collie, R. J., Shapka, J. D., \& Perry, N. E. (2012). School climate and social-emotional learning: predicting teacher stress, job satisfaction, and teaching efficacy. Journal of Educational Psychology, 104(4), 1189. doi:10.1037/a0029356

[14] Covell, K., McNeil, J. K., \& Howe, R. B. (2009). Reducing teacher burnout by increasing student engagement: A children's right approach. School Psychology International, 30(3), 282-290. doi:10.1177/0143034309106496

[15] Creswell, J. W. (2015). Educational research: Planning, conductint and evaluating quantiative and qualitative research. Noida: Pearson India Education Services Pvt. Ltd.

[16] Creswell, J. W., \& Plano Clark, V. L. (2011). Designing and conducting mixed methods research. Thousand Oaks, CA: Sage Publication. doi:10.1177\%2F1049731508318695

[17] Durksen, T. L., \& Klassen, R. M. (2012). Pre-service teachers' weekly commitment and engagement during a final training placement: A longitudinal mixed methods study. Educational and Chil Psychology, 29(4), 32.

[18] Evans, B. (2011). Content knowedge, attitudes and self-efficacy in math New York City teaching fellows (NYCTF) Program. School Science and Mathematics, 111, 225-235. doi:10.1111/j.1949-8594.2011. 00081.x

[19] Fives, H., \& Buehl, M. M. (2009). Examining the factor structure of the teachers' sense of efficacy scale. The Journal of Experimental Education, 78(1), 118-134. doi:10.1080/00220970903224461

[20] Gavora, P. (2010). Slovak pre-service teacher self-efficacy: Theoretical and research considerations. The New Educational Review, 21(2), 17-30. Retrieved from http://www.educationalrev.us.edu.pl/e21/a1.pdf

[21] Giri, M. K. (2014). Teachers' engrosssment in professional development in Surkhet Valley. Journal of NELTA Surkhet, 4, 81-90.

[22] Goddard, R. D. (2001). Collective efficacy: A neglected construct in the study of schools and student achievement. Journal of Education Psychology, 93(3), 467-476. doi:10.1037/0022-0663.93.3.467

[23] Kahn, W. A. (1990). Psychological conditions of personal engagement and disengagement at work. Academy of Management Journal, 33(4), 692-724.

[24] Khany, R., \& Malekzadeh, P. (2015). Associations among EFL teachers' professional identity, professional validity and creativity. Teaching English Language, 9(2), 37-74.

[25] Klassen, R., \& Chiu, M. M. (2010). Effects on Teachers' Self-Efficacy and Job Satisfaction: Teacher Gender, Years of Experience, and Job Stress. Journal of Educational Psychology, 102(3), 741-756. doi:10.1037/a0019237

[26] Martin, N. K., Sass, D. A., \& Schmitt, T. A. (2012). Teacher efficacy in student engagement, instructional management, student stressors, and burnout: A theoretical model using in-class variables to predict teachers' intent-to-leave. Teaching and Teacher Education, 28(4), 546-559. doi: 10.1016/j.tate.2011.12.003

[27] Morgan, D. L. (2007). Paradigms lost and pragmatism regained: Methodological implications of combining qualitative and quantitative methods. J Mix Method Res, 1, 48-76.

[28] Pajares, F. (1995). Curreent direction in self-efficacy research. In M. Maehr, \& P. R. Pintrich, Advances in motivation and achievement (pp. 1-49). Greenwich, CT: JAI Press.

[29] Pajares, F. (1996). Self-efficacy beliefs in educational settings. Review of Educational Research, 66(4), 543578. doi:10.2307/1170653

[30] Pallant, J. (2011). SPSS survival manual. Crows Nest NSW: Allen \& Unwin.

[31] Skaalvik, E. M., \& Skaalvik, S. (2010). Teacher self-efficacy and teacher burnout: A study of relations. Teaching and Teacher Education, 26, 1059-1069. doi: 10.1016/j.tate.2009.11.001

[32] Skaalvik, E. M., \& Skaalvik, S. (2014). Teacher self-efficacy and perceived autonomy: Relations with teacher engagement, job satisfaction, and emotional exhaustion. Psychological Reports, 114(1), 68-77. doi: 10.2466/14.02.PR0.114k14w0

[33] Tashakkori, A., \& Teddlie, C. (1998). Mixed methodology: Combining qualitative and quantative approaches. Thousand Oaks, CA: Sage.

[34] Tschannen-Moran, M., \& Hoy, A. W. (2001). Teacher efficacy: Capturing an elusive construct. Teaching and Teacher Education, 17, 783-805.

International Journal of Research -GRANTHAALAYAH 
[35] Tschannen-Moran, M., \& Woolfolk Hoy, A. (2007). The differential antecedents of self-efficacy beliefs of novice and experienced teachers. Teaching and Teacher Education, 23(6), 944-956. doi: 10.1016/j.tate.2006.05.003

[36] Turkoglu, M. E., Cansoy, R., \& Parlar, H. (2017). Examining relationship between teachers' self-efficacy and job satisfaction. Universal Journal of Educational Research, 5(5), 765-772. doi:10.13189/ujer.2017.050509

[37] Walshaw, M. (2004). A powerful thoery of active engagemnt. For the Learning of Mathematics, 24(3), 4-10. Retrieved from https://www.jstor.org/stable/40248462

[38] Woolfolk Hoy, A., \& Spero, R. B. (2005). Changes in teacher efficacy during the early years of teaching: A comparison of four measures. Teaching and Teacher Education, 21(4), 343-356. doi: 10.1016/j.tate.2005.01.007 